Edi Luketa, mag. posl. znanosti ${ }^{1}$

\title{
TEORIJSKI ASPEKTI KORPORATIVNE KOMUNIKACIJE I NJEZINIH SASTAVNICA
}

\author{
Pregledni rad / Review \\ UDK/UDC: 658.3 \\ DOI: $10.51650 /$ ezrvs.15.1-2.7 \\ Primljeno / Received: 1/4/2021 \\ Prihvaćeno / Accepted: 27/5/2021
}

\begin{abstract}
Korporativna komunikacija u svojoj suštini predstavlja pojam sveobuhvatne komunikacije poslovne organizacije s interesno-utjecajnim skupinama. Sobzirom na njezin značaj u provedbi suvremenih poslovnih trendova i procesa, postala je neodvojivi element u svim poslovnim organizacijama te jedna od ključnih funkcija menadžmenta u korporativnim poslovnim sustavima. Cilj ovog rada bio je steći pregled nad najrelevantnijim znanstvenim teorijama korporativne komunikacije i njezinih temeljnih sastavnica. Unatoč znanstvenicima koji su je definirali brojnim teorijama, zbog njezine sveobuhvatnosti do danas nije postignuto suglasje znanstvene zajednice oko temeljne znanstvene definicije. Dodana vrijednost ovog rada je uvid u teorije najeminentnijih znanstvenih autoriteta u svrhu pregleda sveobuhvatnostipodručja i promišljanja daljnjih znanstvenih istraživanja. Stavljajući dostupne teorije u kontekst brzine poslovnih i tehnoloških promjena kojima se poslovne organizacije moraju prilagođavati, može se zaključiti kako će korporativna komunikacija pratiti procese prilagodbe što će zasigurno rezultirati novim znanstvenim tumačenjima a samim time i otežati postizanje suglasnosti znanstvene zajednice oko temeljne znanstvene teorije.
\end{abstract}

Ključne riječi: teorije korporativne komunikacije, menadžerska komunikacija, marketinška komunikacija, odnosi sjavnošću, organizacija.

\section{Uvod}

Kada promatramo sve procese koji se odvijaju na planeti, bilo prirodne ili ljudske, možemo ustanoviti da je sve proizvodnja, odnosno pretvaranje jednog oblika pojedine materije u drugi. Kao što je i život jedna vrsta proizvodnje tako je i komuniciranje proizvodnja ideja, spoznaja i informacija (Plenković 1991, 5). U proizvodni kontekst, isto tako možemo staviti i organizacije parafrazirajući stih kantautora Tome Bebića „brodovi su isti ka i ljudi“ jer su i organizacije u mnogim elementima baš kao i ljudi. Bez obzira na njihovu svrhu i cilj postojanja, one se rađaju, dobivaju imena, slave rođendane i obljetnice, budu odgovorne za svoje postupke, razvijaju svoj imidž, ugled, osobnost, strukturu i kulturu. U konačnici za njih se emotivno vežemo a one kao i ljudi imaju svoj vijek trajanja. Kako za ljudska bića neupitno

1 Veleučilište u Šibeniku, e-mail: edi.luketa@vus.hr 
vrijedi Wastzlawickov aksiom kako ljudska bića ne mogu ne komunicirati, isto takva teorija vrijedi i za organizacije (Čorić 2019, 9). Promatrajući taj kontekst postaje nam jasno koliko je važna uloga korporativne komunikacije kao organizacijskog elementa bez kojeg ne može opstati organizacija, a bez organizacije naravno ni čovjek. Preduvjet razumijevanju uloge i važnosti korporativne komunikacije kao znanstvene discipline je upoznavanje s njezinim znanstvenim teorijama koje autor navodi citirajući inozemne i tuzemne znanstvene autoritete, što predstavlja i svrhu ovog rada.

\section{Pojmovno određenje i definicije korporativne komunikacije}

Porijeklo riječi komunikacija nalazimo u latinskoj riječi communicare što znači opći, društveni (Fox 2006, 13). Termin Korporativna komunikacija dolazi kao prijevod engleskog termina Corporate Communication koji je pojmovna izvedenica pojma organizacijska komunikacija (Milas 2011, 30). P. Jackson među prvima je dao definiciju korporativne komunikacije kao generirane komunikacijske aktivnosti neke organizacije koja ima za cilj ostvarenje njezinih planiranih ciljeva (van Riel; Fomburn 2007, 25) .Goodman kazuje da je korporativna komunikacija skup internih ili eksternih strateških komunikacijskih aktivnosti na kojima rade stručnjaci u ime organizacije. Karakterizira je kreiranje i održavanje snažnih internih i eksternih odnosa (Goodman 2000, 69-74). Ansgar Zerfass percipirao je korporativnu komunikaciju kao dio organizacijske komunikacije, izuzimajući sve one organizacije koje ne spadaju u poduzetničko ili komercijalno gospodarstvo. Korporativna komunikacija nije samo pojam vezan za komuniciranje velikih tvrtki odnosno korporacija, već korporativna komunikacija podrazumijeva komunikacijske aktivnosti svih poduzeća bez obzira na veličinu (obrt, malo, srednje i veliko poduzeće) uzevši u obzir njihovu poduzetničku aktivnost (Milas 2011, 31-32). Cees van Riel i Charles Fombrun tvrde da se pojam korporativno ne bi smjelo tumačiti kao pridjev koji se odnosi na korporaciju već u kontekstu latinskog izraza corpus (tijelo), na način da se isto tumači kao odnos prema cjelini (Milas 2011, 30 - 32; Riel Fombrun 2007, 26).

Teorije komunikacija i teorija menadžmenta čine teorijsku perspektivu korporativnog komuniciranja. One zajedno stvaraju poligon za analizu odnosa organizacije i njezine okoline, te individualaca i skupina u njezinom okruženju koji imaju utjecaj na organizaciju. Korporativno komuniciranje ima svoju kritičku i retoričku dimenziju koja ima podlogu u teoriji komunikacija. Temelje se na proučavanju retoričkih simbola i strategija u organizacijskoj poruci. Retorička analiza primarno se bavi procesima, učincima i fenomenima komunikacije. "Znanstvenici koji zastupaju retoričke teorije smatraju da je suština utjecaja na odnos organizacije i njenih dionika i javnosti u simboličnom ponašanju jer simbolizam valja promatrati kao suštinu organizacije. Korporativno komuniciranje mora osvijestiti svoju u osnovi retoričku i simboličku ulogu u organizacijskim procesima, osobito procesima stvaranja individualnog i kolektivnog identiteta“( Tafra - Vlahović 2012, 21; Cheney i Dionisopolous 1989).

Kao jedinstvena znanstvena disciplina „korporativna komunikacija je jedna od najmultidisciplinarnijih područja koja se u današnje vrijeme obrađuju na sveučilištima diljem svijeta. Upravo tu multidisciplinarnost čine političke znanosti, ekonomija, filozofija, jezici, semiotika i semantika, kulturalne studije, psihologija, sociologija, komunikologija, metodologija istraživanja, statistika, novinarstvo, računalne znanosti, informacijske tehnologije, mediji, marke- 
ting i oglašavanje, menadžment, poduzetništvo, upravljanje ljudskim potencijalima, gospodarsko pravo i etika" (Oliver 2010, 6-10).

Ansgar Zerfass navodi kako korporativna komunikacija obuhvaća sve važne komunikacijske procese kojima se realizira doprinos prema zadanim ciljevima u tržišnim gospodarskim subjektima. Takvi procesi posebno doprinose kvaliteti interne i eksterne koordinacije djelovanja te suradnji po pitanju usklađivanja interesa između poduzeća i njegovih dionika. Vodeći se tom teorijom, on dijeli korporativnu komunikaciju na internu i eksternu komunikaciju. Internu još naziva organizacijskom komunikacijom dok eksternu komunikaciju dijeli na tržišnu komunikaciju i odnose s javnošću (Milas 2011, 33; Zerfass 2007, 23). Tržišnu komunikaciju možemo definirati kao skup različitih komunikacijskih aktivnosti putem kojih pojedinci ili organizacije nastoje utjecati na primatelja na način da mu kroz slanje poruka različitim medijskim kanalima svoje ideje ili proizvode učine poznatim s krajnjim ciljem kreiranja uvjerenja i stimulacije potražnje (Antolović i Svilčić 2020, 22).

Zoran Tomić, prvi hrvatski autor znanstvenih tekstova na temu korporativnih komunikacija oslonio se na definiciju korporativne komunikacije koju je dao nizozemski profesor korporativne komunikacije Cees B.M. van Riel: „Korporativne komunikacije su instrument menadžmenta pomoću kojeg se što je uspješnije i učinkovitije moguće usklađuju svi svjesno upotrebljavani oblici interne i eksterne komunikacije, kako bi se stvorio pogodan temelj za odnose sa skupinama o kojima tvrtka ovisi" (Milas 2011, 32; Van Riel 1995, 26).

Analizirajući definicije korporativne komunikacije, Mazzei ih je sažela u tri točke: 1. korporativna komunikacija je funkcija upravljanja koja se sukladno korporativnoj strategiji bavi aktivnostima organizacije poslovne komunikacije. 2.Integrira unutarnje i vanjske komunikacijske aktivnosti vezane za rad na korporativnom imidži i reputaciji. 3.Sve spomenute aktivnosti odvijaju se u odnosu s unutarnjim i vanjskim interesno utjecajnim skupinama (Mazzei 2014, 216-230).

Ambijent u kojem danas funkcioniraju suvremene organizacije, zahtjeva od njih pronalazak najboljeg modela komuniciranja. Dinamičnost promjena koje danas nameću globalni trendovi, podrazumijeva konstantno praćenje i prilagođavanje tim trendovima od strane organizacija te usvajanje suvremenih znanja i vještina. Kada se govori u kontekstu korporativnih komunikacija, onda je to primarno realizacija ostvarenja utjecaja organizacija na okruženje te praćenje utjecaja okruženja na organizacije. Konzultantska kuća Watson Wyatt provela je istraživanje čiji su rezultati ukazali na promjenu paradigme a to je da korporativna komunikacija više nije soft funkcija već ključna aktivnost o kojoj ovisi organizacijska uspješnost. $U$ tom istraživanju $88,2 \%$ ispitanika iz struke izjasnilo se da je komunikacija izrazito bitna za izvrsnost u području vodstva organizacije. Istraživanje koje je provedeno među 800 viših direktora iz 19 zemalja, rezultiralo je s podatkom gdje je 49\% ispitanika istaknulo lošu komunikaciju kao najveći uzrok neučinkovitosti u organizaciji (Čorić 2019, 12). S obzirom da organizacijske vizije i misije, sustavi vrijednosti, komunikacijske vizualne percepcije te promišljanja osjećaja i ponašanja imaju izuzetno velik utjecaj na njihovu uspješnost, profesorica Tafra Vlahović naslućuje kako će korporativna komunikacija postati glavni organizacijski faktor u budućnosti (Tafra Vlahović 2012, 73).

Prema Haywoodu, učinkovita korporativna komunikacija treba dati odgovor na sljedeća pitanja: „Tko? (Do kojih interesno utjecajnih skupina se pokušava doći), Što? - poruke (ono 
što se želi razumjeti), Zašto? - ciljevi (što se pokušava postići), Gdje? - doći do ( gdje se interesno utjecajne skupine nalaze), Kada? - raspored (raspored aktivnosti), Kako? - tehnike (predložene metode), Koliko? - resursi (proračun i osoblje), Koliko učinkovito? - procjena (kako će se mjeriti performanse)" (Čorić 2019, 21; Haywood 2002, 52).

\section{Funkcija i sastavnice korporativnih komunikacija}

Prema Cornelissenu korporativna komunikacija je funkcija menadžmenta. Ona organizira i koordinira sve interne i eksterne komunikacijske procese s interesno utjecajnim skupinama o kojima tvrtka ovisi (Cornelissen 2008, 4).

Kada se govori o aktualnim trendovima u korporativnom komuniciranju, onda se govori o novom pristupu komuniciranju koji se još naziva poslovna komunikacija 2.0. Poslovna komunikacija 2.0. temelji se na korištenju novih tehnologija, alata i medija a njezine karakteristike su konverzacija, diskusija, permisivnost, dvosmjernost i višesmjernost, utjecaj, visoka učestalost poruka, mnogobrojni kanali, dijeljenje informacija, dinamičnost, ravnopravnost, amorfnost, kolaboracija, reagiranje i odgovaranje (Bovee, Thill 2012, 3). Zerfass tvrdi kako se funkcija korporativne komunikacije sastoji od interne i eksterne korporativne komunikacije.

Interna komunikacija podrazumijeva komunikaciju s internim utjecajno interesnim skupina (zaposlenici, suradnici, vlasnici) iz povezanih organizacija koje zajedno čine stratešku mrežu.

Eksternu korporativnu komunikaciju čine tržišne komunikacije i odnosi s javnošću. Tržišna komunikacija obuhvaća komunikacijske aktivnosti prema svim interesno utjecajnim skupinama koje su ekonomskim ili tržišnim razlozima povezane s organizacijom. Tu se prije svega misli na kupce odnosno korisnike, dobavljače i konkurentske organizacije. Odnosi s javnošću tako obuhvaćaju komunikacijske aktivnosti s društveno političkim odnosno netržišnim interesno utjecajnim skupinama (Milas 2011, 50-51; Zerfass 2007).

Analizirajući pojam i funkciju korporativne komunikacije, Argenti se oslanjao na trodijelni komunikacijski sustav govornik - tema - slušatelj kojeg je kreirao Aristotel. Tada je pojam govornik preimenovan u komunikator jer taj termin predstavlja širi pojam koji uključuje usmenu i pisanu komunikaciju, novi pojam za slušatelja bila je publika jer uključuje i slušatelje i čitatelje. Navedeni sustav Argenti je proširio tako da je ubacio izbor kanala, kulturološkog konteksta te povratne informacije (response, feedback). Isto tako kad govorimo o korporativnoj komunikaciji, prema Argentiju govornik predstavlja organizaciju, temu komunikacije označavaju simboli tj. poruke i slike dok su slušatelji označeni kao interesno utjecajne skupine (Argenti 1998, 32 - 33).Prema definiciji Cees B. M. Van Riela i Fombruna, funkcija korporativnih komunikacija dijeli se na tri forme korporativne komunikacije: menadžersku ili upravljačku komunikaciju, marketinšku komunikaciju i organizacijsku komunikaciju koja ujedno sadrži više modela organizacijskog komuniciranja. Prema Rielu, od svih navedenih najvažnija je menadžerska komunikacija jer vodstvo preko nje komunicira s vanjskim i unutarnjim ciljanim skupinama (Tafra Vlahović 2012, 18; Van Riel 1992).

S obzirom da znanstvenoj zajednici nisu usuglašene teorije korporativne komunikacije a samim time ni teorije strukturnih podjela, autor preglednog rada oslanja se na Čorićevu teoriju strukturne podjele koja tvrdi da korporativna komunikacija zapravo predstavlja tri međusobno sinergijski isprepletena područja u kojima su sve komunikacijske aktivnosti 
međusobno ovisne. Ta područja nazivaju se menadžerska komunikacija, marketinška komunikacija i komunikacija odnosa s javnošću (Čorić 2019, 21).

\subsection{Menadžerska komunikacija}

Tijekom povijesne evolucije menadžmenta i njegovih teorija, evoluirao je i pojam uloge menadžera koji je u ekonomiji nekad bio usko vezan za pojam zapovjednika u vojnoj organizaciji dok je danas moderni menadžer više učitelj, trener, komunikator, organizator i koordinator nego strogi upravitelj (Gutić, Barbir, 20). Menadžer je ujedno i vođa organizacije ili skupine unutar organizacije a „vodstvo definiramo kao proces u kojem pojedinac utječe na grupu u svrhu postizanja zajedničkog cilja“ (Northouse 2010, 3). Još 1974. godine R.M. Stogdill je u svom istraživanju zaključio kako su ključne sposobnosti uspješnog rukovoditelja inteligencija, razvijeno apstraktno mišljenje, kreativnost, diplomatičnost i taktičnost, dobro usmeno izražavanje, stručnost, organiziranost, uvjerljivost i razvijene socijalne vještine (Yukl 2008, 182). Teorije funkcija menadžmenta također su se tijekom vremena mijenjale pa je tako klasični pristup menadžmentu imao pet funkcija dok inventivni pristup karakterizira osam funkcija: planiranje i strategija, organiziranje, odlučivanje, komuniciranje, motiviranje, inoviranje, kontrola, upravljanje ljudskim resursima (Srića 1994, 13-14).

Uvidjevši sve navedeno, može se zaključiti kao je komunikacija oduvijek bila važna komponenta menadžmenta dok je danas ključan i nezamjenjiv alat na kojem počiva suvremeni menadžment. Ovu tezu jasno potvrđuju i rezultati istraživanja koji su pokazali kako menadžeri bez obzira na razinu menadžmenta između 80\% i 90 \% svog ukupnog radnog vremena provode u komunikaciji. Tu komunikaciju čine $9 \%$ čitanje, $16 \%$ pisanje, 30\% govor i $45 \%$ slušanje (Drucker 2005, 221-224). Menadžersku komunikaciju čine komunikacija misije, vizije, komunikacijske ideologije i organizacijskih ciljeva prema internim i eksternim utjecajnim skupinama kako bi se one s njima senzibilizirale. Ta komunikacija provodi se na svim razinama od strane rukovodstva koji se tijekom komunikacijskog procesa koristi znanjima, vještinama i tehnikama. Tu spadaju također i znanja i vještine iz područja lobiranja s obzirom da su lobistički procesi također neophodni za ostvarenje senzibiliziranja određenih interesno utjecajnih skupina (Čorić 2019, 21). Kada gledamo iz kuta organizacije kao živog mehanizma, komuniciranje omogućava funkcioniranje potrebnih odnosa između individualaca, grupa i organizacijskih jedinica te omogućava sinergijsko djelovanje u svrhu realizacije zadanih organizacijskih ciljeva. Menadžer kao nositelj te komunikacije, treba osigurati njezin neometan protok se osigurati efektivan i kvalitetan komunikacijski sustav (Buble 2009, 576).

\subsection{Marketinška komunikacija}

lako postoji mnogo definicija o marketingu, počevši još od definicije Adama Smitha iz 18. stoljeća, najprecizniju i globalno prihvaćenu definiciju dao je vodeći svjetski autoritet iz tog područja P. Kotler koja kaže da je „marketing društveni proces kojim pojedinci i grupe postižu ono što im je potrebno i što žele, kreiranjem, ponudom i slobodnom razmjenom s drugima, proizvoda i usluga određene vrijednosti“" (Renko 2009, 4-5). Marketing posjeduje četiri funkcije pomoću kojih djeluje a koje optimalnom kombinacijom čine marketinški miks. To su proizvod, cijena, distribucija i promocija (Renko 2009, 8). Kad se govori o marketinškom komuniciranju, 
Čičić i Brkić definiraju ga kao „kontinuiran proces dvosmjernog komuniciranja organizacije sa svojim sadašnjim i potencijalnim kupcima/korisnicima i drugim dijelovima javnosti s ciljem uspostavljanja dugoročnih programa razmjene" (Čičić, Brkić 2001, 3). Kako je važnost marketinga u suvremenim gospodarstvima bila sve veća, usporedno s njim rastao je i značaj marketinške komunikacije, pogotovo s općim prihvaćanjem i rasprostranjenošću novih elektroničkih medija (Kesić 2003, 28). Usporedno s brzim razvojem digitalnih tehnologija, pojavili su se novi prodajni kanali za proizvode i usluge što je uzrokovalo i ključne promjene po pitanju funkcioniranja marketinške komunikacije i njezinih tokova iz razloga što su potrošači dobili nova centralna mjesta preko kojih mogu realizirati svoje potrebe unutar marketinških aktivnosti ( KostićStanković, Vukmirović 2018, 157). Kada se govori u korporativnom kontekstu, marketinšku komunikaciju može se karakterizirati kao oblik korporativne komunikacije koji se financijski stimulira jer je u suvremenom poslovnom svijetu najčešće neophodan poslovni element za ostvarenje prodajnih ciljeva što direktno utječe na ishode korporativne komunikacije. Takvu komunikaciju čine oglašavanje, sponzorstva, direktni marketing, unapređenje prodaje, izravna prodaja te osobna prodaja (Čorić 2019, 21). Kesić definira oglašavanje kao „plaćeni, masovni oblik komunikacije specifičnih sadržaja s ciljem informiranja, podsjećanja i poticanja potencijalnog kupca na akciju u odnosu na određenu ideju, proizvod ili uslugu“ (Kesić 2003, 236). Rouseovi tvrde kako organizacijske poruke koje se plasiraju oglašavanjem obuhvaćaju čvrste kulturne pretpostavke, uvjerenja i društvene vrijednosti ali i kulturna načela, korporativnu etiku, način poslovanja i dr. (Rouse 2005, 219-220). U korporativnom kontekstu, oglašavanje predstavlja neosoban i neizravan oblik komunikacije koji ima ulogu privlačenja pozornosti ciljanih skupina na organizaciju (Čorić 2019, 105). Masterman smatra da je sponzorstvo dogovor dviju strana od kojih jedna plasira financijska sredstva, proizvode ili usluge drugoj strani u zamjenu za određena prava koja se mogu koristiti kao komunikacijske aktivnosti u svrhu ostvarenja dobiti u poslovanju (Čorić 2019, 115; Masterman 2011). Britanske i američke organizacije izravnog marketinga tumače izravni marketing kao interaktivan marketinški sustav koji utječe na mjerljiv odgovor ili transakciju bez obzira na lokaciju te pritom koristi više medija za oglašavanje (Čorić 2019, 112; Yeshin 1998). Luck i Ziegler definiraju unapređenje prodaje kao „izravni poticaj koji nudi dodatnu vrijednost ili stvara zanimanje za proizvod kod prodavača, distributera ili potrošača"( Kesić 2003, 370; Luck i Ziegler 1978). Čorić osobnu prodaju definira kao najučestaliji oblik marketinške komunikacije koji ima za cilj korisnika informirati i motivirati na kupnju putem osobne komunikacije s krajnjim ciljem prodaje ili uspostave dugoročnih poslovnih odnosa. (Čorić 2019, 117).

\subsection{Komunikacija odnosa s javnošću}

Kroz povijest znanstvenici su definirali odnose s javnošću s više od 500 definicija. Prema Glen. M. Broomu odnosi s javnošću mogu se definirati kao "funkcija upravljanja koja uspostavlja i održava uzajamno korisne odnose između organizacije i onih javnosti o kojima ovisi njezin uspjeh ili neuspjeh" (Broom 2010, 7).

Komunikacija odnosa s javnošću može se definirati kao neplaćena komunikacija sa svim internim i eksternim komunikacijskim skupinama koje imaju interes za konstantnim unapređenjem razvojnih ciljeva u svrhu realizacije planiranih tržišnih rezultata. Tu spadaju interna komunikacija, komunikacija s investitorima, upravljanje događajima, krizno komuniciranje, 
korporativna društvena odgovornost i odnosi s medijima (Čorić 2019, 21). Stauss i Hoffman definirali su internu komunikaciju kao komunikacijske akcije koje se planiraju s ciljem kontinuiranog utjecaja na ponašanja, stavove i znanja zaposlenika organizacije (Varey i Lewis $2000,143)$. Komunikacija s investitorima za Tomića predstavlja stratešku funkciju korporativnog menadžmenta koja sinergijskim djelovanjem komunikacija, financija i marketinga kao disciplina, nastoji osigurati korporaciji zadovoljavajuće poslovanje kroz kvalitetnu komunikaciju s potencijalnim i aktualnim investitorima (Tomić 2016, 371). Prema Čoriću, upravljanje događajima predstavlja „skup organizacijskih aktivnosti kojima je cilj razvijanje, održavanje i unapređenje afirmativnog stava i pozitivne percepcije koju različite interesno utjecajne skupine imaju o organizaciji“ (Čorić 2019, 144). Plenković definira krizno komuniciranje kao „znanstvenu i prakseološku disciplinu koja je nastala kao rezultanta (orijentirani dinamički usmjeravajući vektor strukturiranja javnosti) svih mogućih kriznih poruka i komunikoloških zakonitosti, a posebno onih koje se bave ponašanjem čovjeka u opasnostima ili krizama" (Plenković 2015, 113). Matešić i suradnici korporativnu društvenu odgovornost prezentiraju kroz teoriju stvaranja zajedničkih vrijednosti prema kojoj je poslovni subjekt predstavlja nerazdvojni element zajednice koji svojim poslovanjem doprinosi njezinom razvoju ali i participira u svim uspjesima i neuspjesima kao pripadajući čimbenik. (Matešić idr., 2015, 10). Komunikacija s medijima kao korporativna funkcija odgovorna za korporativnu reputaciju prema Belasenu participira u produkciji konzistentnih poruka, uspostavi korporativnog identiteta i njegovom upravljanju te osnaživanju korporativnog imidža i reputacije u javnosti (Belasen 2008, 58).

\section{Zaključak}

Svaka ljudska zajednica bilo obiteljska, poslovna ili neka druga, temelji se na komunikaciji kao alatu bez kojeg njezino formiranje i funkcioniranje ne bi bilo moguće. Upravo zbog prisutnosti komunikacije u svim aspektima života, znanstvenici su definirali stotine teorija bezuspješno tragajući za konsenzusom koji bi je obuhvatio u jednoj definiciji. Zbog njezine sveobuhvatnosti, ništa manje kompleksno nije ni područje korporativne komunikacije stoga možemo zaključiti kako će se isto tako teško pronaći sveobuhvatna teorija koja će znanstvenim konsenzusom biti prihvaćena kao jedinstvena teorija korporativne komunikacije. Promatrajući suvremeni poslovni svijet koji se uvelike temelji na ubrzanom tehnološkom razvoju, korporativnu komunikaciju u budućnosti očekuju brojni izazovi koji će biti usmjereni prije svega na odgovore kako ljudskoj komunikaciji uspješno integrirati suvremene komunikacijske kanale u vidu novih tehnologija, posebno vodeći računa o popratnim aspektima o kojima uvelike ovisi uspješnost komunikacijskih procesa kao što se socijalni i psihološki aspekti jer kao što nam je poznato, nove tehnologije uvelike isključuju neverbalnu komunikaciju a upravo je ona "duša komunikacije“ koja istoj daje najčešće ispravan kontekst $i$ adekvatnu emociju. U svijetu ekspanzije tehnoloških inovacija i brzih organizacijskih promjena, korporativno komuniciranje kao organizacijski element nastaviti će sa snažnim pozicioniranjem u top menadžmentima tvrtki preuzimajući tako direktne odgovornosti za njihove poslovne rezultate. 


\section{LITERATURA}

1. Antolović, Kamilo i Nikša Sviličić. 2020. Komunikacijske vještine. Zagreb: K\&K promocija.

2. Argenti, Paul. 1998. Corporate communication. Boston: Irwin/McGraw-Hill.

3. Belasen, Alan T. 2008. The Theory and Practice of Corporate Communication: A Competing Values Perspective. London: Sage Publications Ltd.

4. Broom, Glen M.. 2010. Cutlip \& Centers Učinkoviti odnosi sjavnošću. Zagreb: Mate d.o.o.

5. Buble, Marin. 2009. Menadžment. Split: Ekonomski fakultet Sveučilišta u Splitu.

6. Cornelissen, Joep. 2004. Corporate Communications, Theory and Practice. London: SAGE Publications Ltd.

7. Courtland, L. Bovee i John V.Thill. 2012. Suvremena poslovna komunikacija. Zagreb: Mate d.o.o.

8. Cees B. M. van Riel i Charles J. Fomburn. 2007. Essential of Corporate Communication. Routledge, Abington.

9. Čičić, Muris i Brkić, Nenad. 2001. Marketing komuniciranje. Sarajevo: Ekonomski fakultet.

10. Čorić, Nino. 2019. Korporativna komunikacija. Mostar: Filozofski fakultet Sveučilišta u Mostaru.

11. Drucker, Peter. 2005. Najvažnije o menadžmentu. Zagreb: MEP Consult.

12. Fox, Renata. 2006. Poslovna komunikacija. Zagreb: Hrvatska sveučilišna naklada.

13. Goodman, Michael B. 2000. Corporate Communication: the American picture. Corporate communications: An International Journal. 5(2), 69-74.

14. Gutić, Dragutin i Vice Barbir. 2020. Psihologija u menadžmentu. Osijek: Studio HS internet d.o.o.

15. Kesić, Tanja. 2003. Integrirana marketinška komunikacija. Zagreb: Opinio d.o.o.

16. Kostić-Stanković, Milica i Valentina Vukmirović. 2018. Tendencije u savremenoj marketinškoj komunikaciji uzrokovane tehnološkim preferencijama generacije ipsilon. Mostar: Časopis FF Sveučilišta u Mostaru. 13(19), 157-182.

17. Matešić, Mirjana, Damir Pavlović i Bino Bartoluci. 2015. Društveno odgovorno poslovanje. Zagreb: VPŠ Libertas.

18. Mazzei, Alessandra. 2014. A multidisciplinary approach for a new understanding of corporate communication. Corporate Communications: An International Journal, 51 (2), 216-230

19. Northouse, Peter G. 2010. Vodstvo: teorija i praksa. Zagreb: Mate d.o.o.

20. Oliver, Sandra. 2010. Public Relation Strategy. London and Philadelphia: Kogan page

21. Haywood, Roger.2002. Corporate Reputation, the Brand and the Bottom Line: Powerful Proven Comunication Strategies for Maximizing Value. London: Kogan page.

22. Plenković, Mario. 1991. Poslovna komunikologija. Zagreb: NIP Alinea Zagreb.

23. Plenković, Mario. 2015. Krizno komuniciranje. Zagreb: Media, culture and public relations 6(2).

24. Renko, Nataša. 2009. Strategije marketinga. Zagreb: Naklada Ljevak d.o.o.

25. Rouse, Michael J. i Sandra Rouse. 2005. Poslovne komunikacije. Zagreb: Masmedia d.o.o..

26. Srića, Velimir. 1994. Inventivni menadžer. Zagreb: MEP Consult.

27. Tafra Vlahović, Majda. 2012. Komunikacijski menadžment: strategija, modeli, planiranje. Zagreb: Visoka škola za poslovanje i upravljanje s pravom javnosti Baltazar Adam Krčelić.

28. Tomić, Zoran. 2016. Odnosi s javnošću: teorija i praksa. Zagreb: Synopsis. 
29. Varey, j. Richard. i Barbara L. Lewis. 2000. Internal marketing: Directions for management. London: Routlege.

30. Yukl, Gary. 2008. Rukovođenje u organizacijama. Zagreb: Naklada Slap.

\section{Summary}

\section{THEORETICAL ASPECTS OF CORPORATE COMMUNICATION AND ITS COMPONENTS}

Corporate communication in its essence is the concept of comprehensive communication of a business organization with stakeholders. Given its importance in the implementation of modern business trends and processes, it has become an integral element in all business organizations and one of the key management functions in corporate business systems. The aim of this paper was to gain an overview of the most relevant scientific theories of corporate communication and its basic components. Despite the scientists who have defined it by numerous theories, due to its comprehensiveness, to this day, no agreement has been reached by the scientific community on a basic scientific definition. The added value of this paper is an insight into the theories of the most eminent scientific authorities for the purpose of reviewing the comprehensiveness of the field and considering further scientific research. Putting the available theories in the context of the speed of business and technological changes to which business organizations must adapt, it can be concluded that corporate communication will follow the processes of adaptation which will certainly result in new scientific interpretations and thus make it difficult for the scientific community to agree on basic scientific theory.

Keywords: corporate communication theories, managerial communication; marketing communication, public relations; organization. 